\title{
MULHERES NO CÁRCERE: A estrutura do sistema prisional e a construção do gênero no Brasil
}

\author{
WOMEN IN PRISON: \\ The structure of the prison system and the construction of gender in Brazil
}

\author{
Luciana Rosar Fornazari Klanovicz* \\ Fernanda de Araújo Bugai*
}

RESUMO: Neste artigo, buscamos pontuar as implicações de gênero do encarceramento feminino a partir da fala de quatro mulheres apenadas no interior do estado do Paraná, Brasil, considerando, para isso, a própria história do sistema prisional no país e a análise das prerrogativas jurídico-legais do ordenamento jurídico nacional.

PALAVRAS CHAVE: Gênero. Prisões. Brasil.

ABSTRACT: In this article, we seek to point out the gender implications of female incarceration through the speech of four distressed women in the countryside of the state of Parana, Brazil, considering for this purpose the history of the prison system in Brazil and the analysis of juridical-legal prerogatives of the national legal order.

KEYWORDS: Gender. Prison. Brazil.

No Brasil, que tem a terceira maior população carcerária do planeta (VERDÉLIO, 2017), a fala de criminosos é praticamente invisível, haja vista que a dimensão do crime não pode ser mais pensada apenas do ponto de vista factual, mas pelas representações simbólicas sobre criminosos perigosos, sobre as pessoas que agem corretamente e sobre as que agem errado. Em outros termos, como observa o historiador Marcos Bretas (MORES; BRETAS, 2017), discutir o lugar desses agentes é discutir como sociedades mobilizam valores, sendo fundamental escapar à noção jurídica do crime e de criminosos para vislumbrar valores negociados em torno das histórias que os envolvem. É preciso, como pontuou a historiadora Sandra J. Pesavento (2009), atuar no contrafluxo da assertiva que entende a cadeia como um esvaziamento da individualidade.

A posição de destaque em termos de população encarcerada ganha outra dimensão quando se observa que o país também tem a quinta maior população de presas (mais de 44 mil), apenas atrás dos Estados Unidos da América (205.400 detentas), da China (103.766), da Rússia (53.304) e da Tailândia (44.751) (PONTES; MARTINS, 2017). Dados oficiais brasileiros mostram que o número de mulheres encarceradas saltou de pouco mais de 5.500

\footnotetext{
* Coordenadora do Centro Interdisciplinar de Estudos de Gênero (CIEG), da Unicentro, Paraná. Visiting Scholar no Lateinamerika Institut, Freie Universität Berlin. Docente e orientadora no Programa de Pós-Graduação Interdisciplinar em Desenvolvimento Comunitário, da Unicentro. Professora Adjunta C do Departamento de História da mesma instituição. Doutora em História (UFSC, 2008), com Pós-Doutorado Interdisciplinar em Ciências Humanas (DICH-ǓFSC, 2011 - Bolsa PNPD-CAPES) e Pós-Doutorado em Gênero e Ciência (Freie Universität Berlin, 02/2017-01/2018).

** Vara de Execuções Penais e Corregedoria de Presídios de Guarapuava/Programa de Pós-Graduação Interdisciplinar em Desenvolvimento Comunitário - Unicentro Mestre em Desenvolvimento Comunitário Unicentro.
} 
em 2000 para mais de 44,5 mil em 2016. Do total de presas, $80 \%$ são mães, responsáveis principais ou únicas pelos cuidados de filhas e filhos; $62 \%$ delas estão cumprindo pena por tráfico de drogas. Do total de presídios, havia 1.420 unidades prisionais estaduais no país, $75 \%$ deles estão destinados a homens, $7 \%$ a mulheres e há $17 \%$ de unidades de uso misto (embora a Lei n. 7.2010, de 11 de julho de 1984 já tenha estabelecido como dever do estado prover presídios para homens e para mulheres) (MINISTÉRIO DA JUSTIÇA, 2014).

Em meio às obrigações do Brasil como signatário de tratados de direitos humanos e de documentos como as Regras de Bangkok, que padronizam procedimentos e tratamento de populações apenadas em nível global, a realidade de encarceramento no interior do país perfaz um caminho que, se não é contraditório às exigências internacionais, no mínimo está muito aquém dos esforços que poderiam já ter sido formulados.

As Regras de Bangkok (Regras das Nações Unidas para o Tratamento de Prisioneiras Mulheres e Medidas Não Restritivas de Liberdade para Mulheres em Conflito com a Lei) foram editadas em 2010, traduzidas para o português brasileiro em 2016, e são complementares às Regras Mínimas das Nações Unidas para o Tratamento de Prisioneiros, de 1955 (QUEIROZ, 2015, p. 6). No entanto, somente em 2010 o discurso feminista fez-se presente na temática inerente ao cárcere.

A atuação do Brasil nas Regras de Bangkok deriva de sua participação como membro da ONU desde a fundação e desde a edição das Regras Mínimas para o Tratamento dos Presos, que já estabeleciam o tratamento não discriminatório e a igualdade entre os sexos (CERNEKA, 2009, p. 1). Cabendo ao Brasil, pela tradição em suas apresentações à organização, uma postura diplomática, política e garantista frente aos enfrentamentos propostos (AMORIM, 2009, p. 68).

Neste artigo, buscamos pontuar as implicações de gênero do encarceramento feminino no interior do Brasil, a partir da fala de quatro mulheres apenadas no estado do Paraná, considerando, para isso, a própria história do sistema prisional no país e a análise das prerrogativas jurídico-legais do ordenamento jurídico nacional.

Assim, abriremos espaço para uma leitura mais detida em torno das intrincadas relações de gênero e violência, por um lado, para depois trabalharmos com o caso de mulheres que cumprem pena em Guarapuava, Paraná, e que puderam relatar suas vivências em meio à situação de privação de liberdade no âmbito de uma pesquisa mais ampla.

O suporte dos casos relatados por quatro prisioneiras proporciona a exploração e o entendimento social de temas mais complexos e amplos, como acontece em meio a estudos de caso. Zaidah Zainal (2007), Grässel e Schrimer (2006) observam que relatos exprimem e permitem a pesquisadores e pesquisadoras examinarem, em contextos específicos, dados já coletados.

Trabalhamos, nesse sentido, com relatos coletados, observando premissas da história oral, considerando as subjetividades, as trajetórias individuais em meio a eventos e processos mais amplos, tais como o da invisibilidade no sistema prisional. Verena Alberti (1989, p. 4) observa que a fonte oral pode acrescentar uma dimensão viva do objeto investigado.

Para apresentar os fragmentos de quatro relatos que obtivemos, tomamos cuidados éticos atinentes ao processo de construção da investigação, garantindo o anonimato e apropriando os relatos sem alterar seus significados e sentidos, com anuência das interlocutoras e autorização do Departamento Penitenciário do Paraná.

\section{Marginalização da presa em meio à marginalização do criminoso}

Se a história de criminosos perfaz um caminho de relativa invisibilidade, de generalizações e de homogeneizações, a construção do sistema prisional calcada na imposição do poder estatal de restrição de liberdade fez com que o ator social criminoso viesse a ser representado sem distinção de gênero. Isso tornou as mulheres, população 
crescente no próprio sistema, ainda mais marginalizadas que os próprios indivíduos criminosos marginalizados homens.

É importante ressaltar que essa situação não é uma exceção, pois é corriqueira e naturalizada em todo o território nacional. Por isso a importância da pesquisa acerca das realidades enfrentadas pelas mulheres presas, mas não apenas isso; é também necessário compreender as motivações que conduziram essas mulheres à criminalidade e o tratamento que lhes é conferido no ambiente prisional. Assim como perceber de que maneira as subjetividades são construídas a partir das vivências dessas mulheres.

Quando não são contempladas com a remoção para uma unidade prisional "adequada", as mulheres encarceradas precisam aguardar a tramitação de seus processos em cadeias públicas, unidades direcionadas unicamente ao sexo masculino, numa situação de improviso e terror, como é possível observar nas falas que coletamos. À marginalização de encarcerados, então, soma-se uma nova marginalização, que é a de mulheres no âmbito do sistema prisional, que pode ter ligações com posicionamentos e formulações realizadas no passado em torno do próprio entendimento jurídico da penalização.

Maria Teresa Citelli (2001, p. 136) identifica que, embora haja certo desconforto referente às obras publicadas no passado, existe uma necessidade em se observar que, quando se fala em sistema penal e criminalidade, ainda é possível percorrer raciocínios que perduram e que tendem a construir o criminoso e a criminosa a partir de diferenças sexuais "naturais".

Eugenio Raúl Zaffaroni (1993 apud ESPINOZA, 2004, p. 21), demonstrou que a relação entre mulheres e sistemas punitivos, no Ocidente, acabou vindo à tona desde os tempos medievais e culminou no século XIX, quando "a relação da mulher com o poder punitivo se revela no processo de gestação desse poder" (ZAFFARONI apud ESPINOZA, 2004, p. 21). Nesse sentido é que é fundamental pensar tal processo como "poder de gênero", ou seja, um sistema de relações no qual a mulher acaba sendo sempre agredida pelo próprio sistema.

Em paralelo, no final do século XIX, como observou Sandra J. Pesavento (2009), uma nova ciência se desenvolvia e se expandia no mundo ocidental: a antropologia criminal. Essa ciência nasceu no espaço urbano, em meio a uma população multiforme, inquieta e ameaçadora. De acordo com Pesavento (2009), "a cidade, local de contraste e da exposição da diferença, apresentava-se sob as suas duas facetas: era tanto o centro difusor das novidades e da cultura quanto era profundamente perigosa, berço de todos os vícios" (PESAVENTO, 2009, p. 5). A sociedade dos homens bons criou práticas e representações para designar o povo desta outra cidade terrível: os excluídos, os indivíduos, os elementos (PESAVENTO, 2009, p. 5).

A perspectiva positivista do "indivíduo", do "elemento", não distinguia homens e mulheres no oceano de indesejáveis sociais. A construção imagética das mulheres como seres fracos de corpo e de mente veio a ser apropriada e aprofundada pela nascente criminologia, e a mulher criminosa passou a carregar, duplamente, a infâmia do crime e a fraqueza biológica.

Por conseguinte, a mulher criminosa passou a ser lida por meio de uma criminalidade inclusive negligenciada, limitada aos contextos da comparação com os crimes de homens, à prostituição e à análise de seu crime a partir de ideias morais como depravação (na perspectiva de que mulheres normais são passivas, não violentas, e de que as mulheres criminosas seriam "anormais" e doentes) (ISLAM et al., 2014).

A marginalização das mulheres criminosas no interior da marginalização do crime veio a ser historicamente construída na medida em que as teorias dominantes de crime (anomia, transmissão cultural ou e conflito) essencialmente localizavam a marginalidade nas classes pobres e no comportamento criminal masculino, daí a sexualização, a psicologização e a silogização dessas mulheres tidas como "loucas".

A partir dos anos 1970, Islam et al (2014) pontuam que uma guinada nos estudos criminalísticos aconteceu e um deslocamento da teoria biológica da causa do crime feminino nas suas mais diversas vertentes paulatinamente para uma leitura do crime a partir das 
relações de gênero passou a acontecer no âmbito da discussão teórica. Primeiro, surgiram estudos destinados a dar visibilidade às mulheres criminosas (ISLAM et al., 2014). Mais recentemente, Walklate (2003) considerou a necessidade de perceber as nuances de gênero na construção de homens e mulheres do crime na medida em que o crime é uma atividade preponderantemente masculina, mas não é o resultado de diferenças sexuais. Ele é o produto de diferenças de gênero (ISLAM et al., 2014).

Espinoza (2004, p. 84-85) destaca que a mulher presa "tem sido estudada sob o estereótipo de mentalmente perturbada", e que tal postura decorre de estudos psicogenéticos da criminalidade que ainda pautam a promoção de políticas públicas voltadas ao combate da criminalidade, especialmente no âmbito da saúde. A realidade de construção dessas políticas com base na adoção de tais posturas pode estar diretamente ligada à ineficácia que o poder público apresenta frente à existência de milhares de mulheres encarceradas no Brasil e da rápida expansão desses números em anos recentes (ESPINOZA, 2004, p. 84-85).

O exercício do discurso jurídico e prisional de naturalização do sexo é uma maneira de assegurá-lo em um status pré cultural, pré discursivo, de acordo com o que pontua a filósofa Judith Butler (2010). Butler (1998) entende que o uso da categoria "mulher" é coerente para reivindicação política, que é multifacetada e, em razão disso, sua proposta é esquecer as identidades que rotulam, fixando realidades numa alegoria de masculino/feminino, propondo-se pensar o poder que permeia a constituição desta mulher, todo o processo que esta passou para hoje se tornar um "agente", explorando a ideia de liberdade do sujeito estar "aberto" para novos enfrentamentos e realidades, vigorando e ressignificando sua constituição.

Conhecer a existência ou a invisibilidade da mulher no sistema prisional, seus motivos para o cometimento de delitos é, assim, tarefa crucial para a delimitação desse universo, refletindo-se diretamente na sociedade, nas perspectivas de segurança pública e combate à violência.

\section{Historiando o sistema prisional}

Embora etimologicamente não seja possível precisar a origem da palavra pena, entende-se que sua origem derive do termo latino poena, que significa castigo, expiação e suplício, ou dos outros termos punere (por) e pondus (preso), no sentido de pesar, em face ao equilíbrio que se estabelecia pela ideia de balança da justiça. Ainda, é possível posicionar sua origem a partir das palavras gregas ponos e poiné, que implicam noções de trabalho, fadiga e sofrimento (BECCARIA, 2011).

Até o século XVIII, em contexto amplo, as penas e a história do direito penal são marcadas pela crueldade, pelo suplício, não sofrendo interferência de posturas humanísticas. Ainda mais porque a esfera do crime estava ligada à esfera do pecado (FOUCAULT, 1999) de modo que inexistia o pensamento da privação de liberdade como pena, mas unicamente no sentido de custódia que evita a fuga, para a garantia do processo penal.

Foi apenas no século XVIII que a pena privativa de liberdade surgiu enquanto meio de punição estatal, como forma de exercício da punição, a partir da escola criminológica positivista, que deu caráter punitivo, retributivo e preventivo à pena.

Foi no final do XVIII que começaram a surgir os primeiros projetos do que se tornariam as penitenciárias, ainda hoje modelos utilizados em diversos países. Nesse aspecto, destacam-se nomes como John Howard e Jeremy Bentham, ingleses que, após a vivência cotidiana com pessoas criminosas e imersos no universo da criminologia, fizeram propostas para a reforma do sistema punitivo. Segundo Bentham, "a disciplina dentro dos presídios deve ser severa, a alimentação grosseira e a vestimenta humilhante". Apesar do pensamento radical, foi a partir daquele momento que surgiram as estruturas penitenciárias ainda hoje utilizadas como modelos, em que se busca a disciplina e a punição (GONÇALVES, 2009, p. 11). 
Os modelos de estrutura penitenciária são variáveis no decorrer dos séculos, apostando-se nas mais diversas estruturas físicas para conter a pessoa presa, destacandose, especialmente, a situação de reclusão absoluta do preso, deixando-se de lado a importância da ressocialização e o pensamento de que a pessoa em algum momento retornaria ao convívio social

Nesse contexto, Michel Foucault (2014, p. 223) assevera que a mudança no meio de punição acompanha a tendência de mudanças políticas da época - note-se que a análise contextual é eurocêntrica, em razão de se tratar da maior influência ao sistema prisional brasileiro. $\mathrm{O}$ autor destaca que a prisão, naquele momento, modifica o meio de sofrimento do sujeito, deixando-se a punição do corpo e passando a se punir sua "alma".

Para Foucault $(2014$, p. 23) o sistema penal organizado permite à sociedade "organizar, acomodar, tornar política e economicamente vantajoso todo um jogo de ilegalidades e ilegalismos", de maneira a manipular a população carcerária - já excluída - a agir de acordo com os interesses do Estado. Afinal, para o autor o sistema penitenciário nada mais é do que a efetivação de um sistema de poder, imposto pelo mais forte àquelas pessoas que se mostram como atores dessa sistemática de um sistema "em toda a extensão dos efeitos de poder que eles trazem, por meio da colocação de novas objetividades" (FOUCAULT, 2014, p. 301).

O Brasil não teve um sistema de ordenamento jurídico penal até 1830 (RIBEIRO JUNIOR, 2009). O império recente acabou por utilizar as Ordenações Filipinas portuguesas, que em seu livro $\mathrm{V}$ traziam o rol de crimes e penas que seriam aplicados. Entre elas, previam-se as de morte, degredo para as galés e outros lugares, penas corporais (como açoite, mutilação, queimaduras), confisco de bens e multa e ainda penas como humilhação pública do réu. Não estava previsto o cerceamento e a privação de liberdade, uma vez que as Ordenações são do século XVII e os movimentos reformistas penitenciários começam só no final do século seguinte. Os estabelecimentos prisionais do Brasil seguiam o antigo entendimento de prisão como meio de evitar a fuga para a pena que viria e não como pena final (MAIA, 2009, p. 5-7).

Em 1824, com a primeira Constituição Federal, foi que o Brasil começou a reformar seu sistema punitivo, humanizando a pena e deixando de lado, ainda que timidamente, a utilização da pena cruel e corporal. E foi em 1830, com o Código Criminal do Império, que surgiu a pena de prisão, subdividida em duas categorias: a prisão simples e a prisão com trabalho (que podia ser perpétua); predominantes entre as penas a serem aplicadas, todavia, mantendo-se a possibilidade da pena de morte e dos trabalhos forçados. Naquele momento, o Estado não definiu um modelo próprio de sistema penitenciário, ficando tal decisão à incumbência das províncias, estabelecendo-se, no entanto, a necessidade da existência de acomodações à pessoa presa que satisfizessem também a necessidade do trabalho.

Em 1841, o Brasil abriu espaço para os modelos de sistemas penitenciários estrangeiros e, assim, foram criadas as casas de correção de São Paulo e Rio de Janeiro, modelos influenciados pelo pensamento de Jeremy Bentham (GONÇALVES, 2009, p. 11). As duas casas de correção eram exceções frente ao sistema falido já àquela época. Ademais, ambas apresentavam o modelo de ressocialização pelo trabalho que, muitas vezes forçado, passou a gerar grandes críticas sociais (ARAỦJO, 2007, p. 154).

Em 1890, a criminologia positivista passou a influenciar os pensadores penais no Brasil e, nessa época, o novo Código Penal aboliu as penas de morte, penas perpétuas, açoite e as galés, e previa quatro tipos de prisão: a prisão celular, reclusão em "fortalezas, praças de guerra ou estabelecimentos militares" destinada para os crimes políticos contra a recém-formada República; prisão com trabalho a ser cumprida em penitenciárias agrícolas e prisão disciplinar, destinada aos menores de 21 anos. Nesse momento, o novo código assumiu o modelo de sistema progressista irlandês, responsável pela progressão gradativa do sujeito enquanto cumpria sua pena. 
Mesmo existindo novas visões e a preocupação com a ressocialização da pessoa presa, a realidade carcerária do Brasil era desastrosa, inexistindo, naquele momento, unidades prisionais suficientes para o número de pessoas presas.

Segundo Fernando Salla (2006, p. 189), no ano de 1906, foram condenados no Estado de São Paulo 976 presos à prisão celular. Existiam apenas 160 vagas para esse tipo de prisão no estado, portanto 816 presos cumpriam pena em condições diversas àquela prevista no Código Penal vigente. Observamos, portanto, que o problema de superpopulação é contemporâneo ao surgimento desse modelo prisional.

Pouco se fala na literatura acerca do sistema prisional no Brasil nesse período de reforma e reestruturação, afinal, cada estado-membro era responsável pelo sistema prisional correspondente, que acabou sendo caracterizado pelos males que sempre estiveram presentes em presídios, como a violência e a arbitrariedade dos funcionários e responsáveis, principalmente no caso de punições (DI SANTIS; ENGBRUCH, 2012).

A situação prisional se arrastou e, em 1940, editou-se o novo Código Penal Brasileiro, vigente até o momento. Nele, o legislador trouxe inspirações europeias, apresentando uma lei fundamentada em bases de um direito punitivo democrático e liberal, ainda que dentro de um regime ditatorial. A mudança de código não trouxe maiores modificações no sistema prisional adotado, sendo que, somente em 1984, foi promulgada a Lei de Execuções Penais $n .{ }^{\circ} 7210$ (LEP), responsável pela regulamentação do sistema carcerário no Brasil que vigora até o momento. Conforme já disse Cezar Roberto Bitencourt (2017, p. 39), "a história da prisão não é a de sua progressiva abolição, mas de sua reforma", sendo concebida como um mal necessário, que, no entanto, guarda contradições e mecanismos de poder insolúveis. Merece destaque a argumentação de Michel Foucault (2014, p. 300) quanto à reestruturação dos modelos encarceramento.

Verificamos, assim, que o modelo estruturado de vigilância carcerária imposto no Brasil serve de mecanismo de disciplina e autoridade exercida pelo estado, e é impossível tratar de Estado sem adentrar o mérito das distinções do público e do privado, conforme veremos adiante.

\section{Sistema prisional feminino}

No Brasil, a Lei n. 7.210/1984 é conhecida, no âmbito da história do direito nacional, como um marco inovador e foi recepcionada pela Constituição Federal de 1988. Segundo Pietro de Jesus Lora (2007, p. 244-245) "a tendência dos ensinamentos constitucionais é no sentido de reconhecer e valorizar o ser humano como a base e o topo do direito", especialmente por atentar-se às diretrizes de cidadania e direitos humanos.

De maneira ampla, conforme destacam Garutti e Oliveira (2012), são cinco pontos fundamentais estabelecidos pela Lei no que diz respeito à classificação de unidades prisionais no território brasileiro. A primeira classificação fala da Unidade Penitenciária, que é destinada à pena de reclusão, em regime fechado (Art. 87). A segunda são as Colônias Agrícolas, Industriais ou similares, ou seja, estabelecimentos construídos para abrigar presos de justiça cujo cumprimento da pena seja em regime semiaberto (Art. 91). Em seguida, existe a casa do albergado, para presos cujo cumprimento de pena privativa de liberdade seja em regime aberto e a pena de limitação de final de semana. Nesses estabelecimentos, presos trabalham normalmente durante o dia e recolhem-se à noite (Art. 93). Há ainda hospital de custódia e tratamento psiquiátrico, destinado a inimputáveis e semi inimputáveis (Art. 99), ou seja, "as pessoas portadoras de doença mental ou desenvolvimento mental incompleto ou retardado, desde que comprovado que o agente era portador dessa doença quando da prática da transgressão criminal e que era inteiramente incapaz de entender o caráter ilícito do fato" (Art. 26). E, por fim, a cadeia pública, estabelecimento construído próximo de centros urbanos e destinado a presos provisórios, ou seja, antes da sentença condenatória definitiva (Art. 102).

Trata-se da lei que trouxe avanços evidentes no sistema penitenciário brasileiro, já que, antes de 1984, a execução de pena era apenas um expediente administrativo, mero 
consectário legal e lógico da condenação, o que não significa que as previsões legais tenham sido alcançadas (CARDOSO, 2009, p. 107-108).

A Lei estabeleceu que as mulheres devem ser custodiadas em estabelecimentos prisionais adequados às suas condições pessoais, o que veio a ser consagrado pela Constituição de 1988 como dever do Estado, representando aspecto fundamental para a implementação de políticas públicas específicas, voltadas a esse segmento.

De acordo com o levantamento bibliográfico realizado, embora seja vasto o acervo de trabalhos científicos que discutem gênero e encarceramento feminino, pode-se observar que são poucas as informações acerca da existência e das condições das unidades prisionais no Brasil. As pesquisas existentes tratam de análises in loco. Existem poucos assentamentos oficiais acerca do cumprimento da previsão legal, notadamente no Direito, que, seja por ironia ou por excesso de conservadorismo, detém uma amplitude reduzida de trabalhos nessa temática, especialmente naquela voltada para as mulheres - situação que está mudando gradativamente - mas ainda se mostra tímida quando comparada a produções das áreas interdisciplinares, da história, do jornalismo e até mesmo da saúde.

Heidi Ann Cerneka (2009), quando coordenadora da Pastoral Carcerária Nacional, publicou Homens que menstruam, onde afirma que "o sistema prisional no Brasil e no fundo foi criado por homens e para homens" (CERNEKA, 2009, p. 61). A partir de dados quantitativos, ela demonstrou as diferenças de tratamento conferidos a homens e mulheres presos(as) no Brasil, que repercutem no pensamento das políticas públicas. Sua obra serviu de inspiração para o livro jornalístico de Mariana Lucena Queiroz, Presos que menstruam, (2016), com uma série de entrevistas realizadas com detentas e ex-detentas de várias unidades prisionais do Brasil, de norte a sul do país, mostrando a realidade da prisão e da criminalidade brasileira a partir da narrativa pessoal de sete personagens.

Em São Paulo, Drauzio Varella relatou seu cotidiano como médico voluntário, desde 2006, na Penitenciária Central do Estado. Numa trilogia que se iniciou com Estação Carandiru, em 1999, prosseguiu com Carcereiros, em 2012, e, somente em 2017, com Prisioneiras, o autor trouxe contos e histórias de vida através de suas memórias e entrevistas com pessoas que fizeram parte de seu cotidiano, relatando tanto suas subjetividades quanto das personagens, onde apareceu a situação caótica dos estabelecimentos prisionais a que se referiu a obra.

Nessa mesma linha, a antropóloga Debora Diniz publicou Cadeia: relato sobre mulheres (2015), dando destaque às vivências no interior do Presídio Feminino do Distrito Federal. A partir de 50 relatos coletados num período de seis meses de visita, a autora apresentou sua visão antropológica da condição de ser mulher e presa.

Os trabalhos acima citados são aqueles que causaram frenesi, se tornaram notícias midiáticas e assuntos comentados até surgirem novas pautas. Entrementes, no que tange ao Direito e às constatações do sistema penal voltado às mulheres, a simples busca pelo termo "encarceramento feminino", dentro das plataformas de pesquisa nacionais, pode trazer resultados que ultrapassam o número de 10.000 publicações, e, dentre elas, em sua maioria, os trabalhos são recortes de um vasto trabalho de campo desempenhado.

As mulheres e a vivência pós-cárcere (2015), de Elaine Pimentel, foi fruto de tese de doutorado em sociologia na Universidade Federal de Pernambuco e mostrou a vivência de quatro mulheres na cidade de Alagoas, que dividiram com a autora suas expectativas pessoais e sociais, bem como suas vidas dentro e fora das prisões.

Magali Oliveira e André Filipe Santos (2012) publicaram Desigualdade de gênero no sistema prisional: considerações acerca das barreiras à realização de visitas e visitas íntimas às mulheres encarceradas, discutindo as diferenciações impostas pelo sistema prisional ao direito de visita e visita íntima das mulheres e dos homens presos, destacando a essencialidade desses direitos para a manutenção dos laços familiares e afetivos dos reclusos.

Já Luiz Antônio Bogo Chies e Adriana Batista Varela (2007), em A ambiguidade do trabalho prisional num contexto de encarceramento feminino: o círculo vicioso da exclusão, analisaram o trabalho de mulheres encarceradas a partir de dados coletados no presídio de 
Pelotas/RS, confrontando-os com pesquisas realizadas em outros estados brasileiros e problematizando a relação de poder e de políticas públicas.

Prisão e políticas públicas: uma análise do encarceramento feminino no estado do Ceará, de Ana Gabriela Mendes Braga e Paula Pereira Gonçalves Alves (2015), debateu o modelo de políticas públicas destinadas às mulheres presas no Ceará, a partir da experiência do próprio estado, através de entrevistas realizadas no local, com enfoque sobre o paradoxo entre superinvestimento em segurança pública e escassez de políticas sociais.

Fernanda de Magalhães Dias Frinhani e Lídio de Souza (2005), em Mulheres encarceradas e espaço prisional: uma análise de representações sociais, analisaram a condição das mulheres presas no Espírito Santo. Mulheres nas so $(m)$ bras: invisibilidade, reciclagem e dominação viril em presídios masculinamente mistos, de Leni Beatriz Correia Colares e Luiz Antônio Bogo Chies (2010), deslocou o olhar sobre as populações presidiárias no tocante a questões de gênero. Outros trabalhos têm discutido a distribuição demográfica prisional feminina em várias regiões do país (SCHERER et al., 2011).

No campo do Direito, os livros até então disponíveis trazem o histórico prisional de forma abrangente e são ainda modestas, na área da Criminologia, obras voltadas à questão feminina, podendo-se destacar Criminologia feminista: novos paradigmas, de Soraia da Rosa Mendes (2014), que traz um paradigma conceitual e histórico acerca da construção do sistema prisional e do espaço destinado à mulher, suas experiências históricas, o paradigma etiológico e a epistemologia feminista.

O jurista Rogério Greco (2016), em Sistema prisional: colapso atual e soluções alternativas, aborda os fundamentos e limitações da pena e a legitimidade do Estado para punir, traçando a análise pela ótica dos direitos humanos, origem e evolução histórica da pena e da prisão. Ele analisa obras de pensadores da temática, fazendo uma explanação dos atuais problemas e enfrentamentos da privação de liberdade no Brasil e suas alternativas. Embora a obra faça uma análise globalizante do sistema prisional atual, partindo do aspecto histórico, deixa de lado a perspectiva de gênero, expiando o universo do dever ser.

Essa ausência de dados e trabalhos específicos acerca do sistema prisional no Brasil se deve também à ausência de informações disponibilizadas pelos governos. Nesse sentido, ou a pesquisa trata do universo de maneira ampla e mais distanciada, ou há a necessidade de empenhar esforços empíricos para tratamento do tema que, num país de dimensões continentais, tem em cada região uma face distinta de encarceramento.

Em razão disso, o Departamento Penitenciário Nacional só passou a coletar e disponibilizar dados sobre as unidades prisionais a partir de 2004, 20 anos depois da Lei. Esses dados passaram a ser publicados em documento oficial, o Infopen.

O levantamento de dados passou a incorporar a dimensão de gênero na elaboração dos quadros estatísticos do sistema prisional tardiamente, quando as Regras de Bangkok passaram a ser disponibilizadas em língua portuguesa na plataforma eletrônica do Conselho Nacional de Justiça (CNJ).

Ainda em 2016, o então presidente do CNJ, Ricardo Lewandowski, destacou a importância do olhar penitenciário direcionado à mulher, salientando o aumento significativo do aprisionamento feminino no país e seus impactos para políticas de segurança, para a administração penitenciária e para políticas de combate à desigualdade de gênero, temática que encontrava eco nas Regras de Bangkok.

As regras de Bangkok datam de muito antes de 2010, quando foram compiladas, e dirigem-se à condição essencial da mulher em situação de prisão. Com olhar direcionado aos seus anseios e sua luta, social, de classe, de gênero, são "regras das Nações Unidas para o tratamento de mulheres presas e medidas não privativas de liberdade para mulheres infratoras" (BRASIL, 2016).

O nascer da temática é anterior e influenciado por demais tratados que versam sobre direitos humanos, como as Regras Mínimas das Nações Unidas para o Tratamento de Prisioneiros (Resolução 1984/47), as Regras de Tóquio (Resolução 45/110), a Declaração de Viena sobre Crime e Justiça: ao Encontro dos Desafios do Século XXI (Resolução 
55/59), as Recomendações para o Cuidado Alternativo de Crianças (Resolução 64/142), a Declaração de Salvador sobre Estratégias para Desafios Globais de Prevenção do Crime, Sistema de Justiça Criminal e seus Desafios em um Mundo em Transformação (A/CONF. 213/18, cap. I, resolução 1), além dos princípios básicos da Declaração Universal dos Direitos do Homem e Declaração dos Direitos da Criança, entre outros tratados, disponíveis na plataforma digital do Conselho Nacional da Justiça (BRASIL, 2017).

Desde 1948, o Brasil faz parte da ONU como membro fundador, fazendo-o detentor do dever de respeito pelas regras que a entidade edita, embora não possa sofrer sanção por não cumpri-las. Ocorre que, em maio de 2012, o Brasil foi sabatinado na Revisão Periódica Universal da ONU, em Genebra. Na oportunidade, 78 outros países fizeram recomendações pontuais ao Brasil em razão da constante violação de direitos humanos. A questão do aprisionamento de mulheres mereceu destaque "como um problema particular, revelando que tanto autoridades quanto organizações não governamentais já estão sendo influenciadas por 16 ideias feministas no âmbito da discussão internacional de direitos humanos na questão específica da privação de liberdade", segundo Mariana Lucena de Queiroz (2015, p. 16).

Das recomendações sugeridas, o Brasil apoiou todas aquelas pertinentes à superlotação, execuções, direitos das mulheres, combate à tortura, melhoria no acesso a equipes de monitoramento e acesso à Justiça (BRASIL, 2012). A sabatina ocorreu em 2006 e repetiu-se em 2017, quando recomendações inerentes aos direitos humanos no âmbito nacional elevaram-se para 240 (BRASIL, 2017).

As Regras de Bangkok compreendem 70 diretrizes categorizadas que disciplinam 0 tratamento da mulher presa e infratora dentro e fora das unidades prisionais, em aspectos de estruturação de unidades prisionais, sistemas de assistência, saúde, educação, dinâmica das relações interpessoais dentro das unidades, políticas de atendimento e defesa de mulheres, dentre outros fatores. Destacam-se, por ora, a primeira e a última regra, que são:

1) A fim de que o princípio de não discriminação, incorporado na regra 6 das Regras mínimas para o tratamento de reclusos, seja posto em prática, devese ter em consideração as distintas necessidades das mulheres presas na aplicação das Regras. A atenção a essas necessidades para atingir igualdade material entre os gêneros não deverá ser considerada discriminatória, e

70) 1. Os meios de comunicação e o público serão informados sobre as razões pelas quais as mulheres entram em conflito com o sistema de justiça criminal e as maneiras mais eficazes de lidar com essas situações, com o intuito de permitir a reintegração social das mulheres, considerando o melhor interesse de seus filhos/as. 2. Publicação e disseminação da pesquisa e exemplos de boas práticas deverão formar elementos amplos de políticas que visem melhorar os resultados e a igualdade das respostas do sistema de justiça criminal para mulheres infratoras e seus filhos/as. 3. Os meios de comunicação, o público e aqueles com responsabilidade profissional no que se refere às mulheres presas e infratoras terão regular acesso a informações factuais acerca dos temas contemplados nestas regras e sobre sua implementação. 4. Programas de capacitação sobre as presentes regras e os resultados de pesquisas serão desenvolvidos e implementados para funcionários/as competentes da justiça criminal com o intuito de elevar sua consciência e sensibilidade sobre as disposições contidas nessas regras. (BRASIL, 2017).

Embora o Brasil tenha referendado tais regras, observa-se que muito pouco está sendo praticado dentro dessa perspectiva. Desde a disposição das estruturas físicas que devem ser dispensadas à mulher presa, já prevista na legislação de 1984, ratificada em Bangkok em 2010 e timidamente aplicada pelo Superior Tribunal de Justiça, há de se notar, portanto, que não é desconhecido pelo Estado em nenhum dos seus três poderes (legislativo, executivo e judiciário) a existência da mulher no sistema penitenciário. 
Em grau de comparação, conforme tabelas abaixo, pode-se observar os números correspondentes à população carcerária brasileira, excluindo-se as unidades federais, em cotejo ao número de unidades prisionais e vagas oferecidas, nos anos de 2005, 2014 e 2016 (Quadros 1 e 2).

Quadro 1 - População carcerária no Brasil (2005-2016)

\begin{tabular}{l|l|l|l}
\hline BRASIL & $\mathbf{2 0 0 5}$ & $\mathbf{2 0 1 4}$ & $\mathbf{2 0 1 6}$ \\
\hline $\begin{array}{l}\text { POPULAÇÃO CARCERÁRIA } \\
\text { TOTAL }\end{array}$ & 296.919 & 579.797 & 726.712 \\
\hline HOMENS & 283.994 & 542.407 & 665.482 \\
\hline MULHERES & 12.925 & 37.380 & 42.355 \\
VAGAS & 206.559 & 371.884 & 368.049
\end{tabular}

Fonte: DEPEN, 2014-2017.

Quadro 2 - Unidades prisionais no Brasil (2005-2016)

\begin{tabular}{l|l|l|l}
\hline BRASIL & $\mathbf{2 0 0 5}$ & $\mathbf{2 0 1 4}$ & $\mathbf{2 0 1 6}$ \\
\hline UNIDADES & 879 & 1420 & 1449 \\
\hline MASCULINAS & 798 & 1070 & 1067 \\
\hline FEMININAS & 81 & 103 & 107 \\
\hline MISTAS & & 239 & 244 \\
NÃO INFORMADAS & & 8 & 31
\end{tabular}

Fonte: DEPEN, 2014-2017.

No que se refere à população carcerária feminina, ocorreu um aumento de presas de aproximadamente $350 \%$ durante os períodos ora expostos, passando de 12.925 mulheres presas para 42.355, num intervalo aproximado de onze anos, nitidamente em descompasso com o número de vagas ofertadas, senão vejamos (Quadro 3):

\section{Quadro 3 - Vagas e deficit de vagas em unidades prisionais no Brasil (2005-2016)}

\begin{tabular}{l|l|l|l}
\hline BRASIL & $\mathbf{2 0 0 5}$ & $\mathbf{2 0 1 4}$ & $\mathbf{2 0 1 6}$ \\
\hline VAGAS & 206.559 & 371.884 & 368.049 \\
\hline DEFICIT & 154.843 & 250.318 & 358.663
\end{tabular}

Fonte: DEPEN, 2014-2017.

Sobre o tema, Julita Lemgruber (1999, p. 6), ao analisar as diferenças nas taxas de criminalidade entre homens e mulheres, apontou que "prendem-se, sobretudo, a fatores socioestruturais [...] na medida em que as disparidades sócio-econômico-estruturais entre os sexos diminuem, há um aumento recíproco da criminalidade feminina" (LEMGRUBER, 1999, p. 6).

Além de se mostrar em desacordo com a previsão da Lei de Execução Penal, o sistema prisional hoje revela sua ineficiência quanto ao cumprimento das leis, bem como o 
agir em desacordo com os tratados internacionais assinados. O crescimento da população prisional feminina é latente, enquanto a oferta de vagas e unidades próprias não acompanham tais índices.

Todavia, esse esquecimento e essa não visibilidade explica-se por motivos muito mais antigos e multifacetados que apenas a estrutura jurídico-penal assumida pelo Estado. Mas por uma sistematização de estruturas de poder, conforme já prenunciado por Foucault (1999), por se tratar o sistema penal nada mais do que a estruturação repressiva das relações humanas.

\section{Relatos de mulheres presas da cadeia pública de Guarapuava, no Paraná}

No Estado do Paraná, de acordo com os dados fornecidos pelo Departamento Penitenciário (Depen), existem três unidades prisionais femininas, localizadas nas cidades de Curitiba e Foz do Iguaçu. Ou seja, os locais destinados ao cárcere de mulheres estão nos extremos leste e oeste do Estado, em regra, responsáveis pela absorção do número total de presas oriundas dos 399 municípios do Estado.

Ocorre que a realidade fática é diversa. Essas três unidades prisionais não absorvem o número total de mulheres presas, por uma infinidade de fatores, de forma que tais pessoas são segregadas em delegacia de polícia e carceragens de cadeias públicas, onde permanecem durante todo o período da ação penal e muitas vezes durante o cumprimento da pena.

Essa realidade ocorre possivelmente em todos os locais que dispõem de delegacias de polícia. Muitas vezes a motivação é a manutenção do vínculo familiar conforme ocorre no município de Guarapuava, onde foram entrevistadas quatro mulheres presas: Mila (2018), Carol (2018), Helena (2018) e Sandra (2018), que, dentro de suas próprias subjetividades, demonstraram a realidade do sistema como um todo, desde o gerenciamento até essa reafirmação da estrutura de gênero representada pelas relações de domínio.

Apesar de se tratar de unidade prisional destinada unicamente a presos provisórios do sexo masculino, cuja capacidade é para 166 presos, atualmente conta com mais de 380 pessoas encarceradas, das quais mais de 30 são mulheres, sejam elas presas provisórias ou já condenadas, nos regimes fechado ou semiaberto, de maneira improvisada, a partir da disponibilização de uma única cela feminina e um quarto improvisado na cozinha.

A realidade da cadeia pública de Guarapuava não é diferente da realidade de muitos municípios do Brasil, razão que justifica sua explanação nesse estudo.

Questionadas sobre quais são as suas percepções após o episódio de prisão, Mila observou que "Aqui depois que eu vim presa é bem complicado, lá fora você sai a hora que você quer, faz o que quer, você se manda né. $E$ aqui não, aqui você tem horário pra tomar sol, você tem horário pra vim pra aula, tem horário pra voltar, você só sai se o funcionário abrir se o funcionário não abrir não sai, é bem complicado até acostumar no ambiente [...]" (MILA, 1 mar. 2018).

Carol, acompanhando a perspectiva de Mila, constatou que sua vida mudou radicalmente com o encarceramento, em todos os sentidos, em especial à liberdade. De acordo com ela, "Minha vida depois da prisão mudou totalmente né, porque lá fora tem/tinha aquela liberdade de ir e vir, aqui dentro já não tem né, você é privado de muita coisa, até mesmo de comida. Assim, quando você ta no fechado não é tudo que entra, tudo que pode utilizar, mas lá fora não, lá tem acesso a tudo o que quiser. [...]" (CAROL, 27 fev. 2018).

Helena (2018) observou sua realidade a partir de uma perspectiva de tristeza, considerando que "é complicado viver com pessoas que você nunca viu na vida, tem que se adaptar porque você sabe que não vai embora" (HELENA, 26 fev. 2018). E continuou, "aqui dentro você vive de esperança, a cada fato que surge de ir pra casa é uma esperança, é uma felicidade (HELENA, 26 fev. 2018). Helena não teve sorte em seu primeiro casamento, relatou que o marido se envolveu com a criminalidade e que, por conviverem na mesma casa, quando ocorreu o flagrante daquele, segundo ela, num dia em que estava trabalhando fora, sequer estava no local, não teve espaço para fala ou para defesa. Foi indiciada, 
processada e julgada, anos mais tarde, quando havia constituído nova família - agora "com um homem decente" -, sendo então presa. Helena é a única das mais de trinta mulheres na Cadeia Pública de Guarapuava que recebe visita do marido, recebe ainda apoio da família, sempre presente, realidade distante das tantas outras presas, que, eventualmente, pode acentuar o sentimento melancólico.

Além do anseio pela liberdade e da drástica mudança que ocorreu em suas vidas, essas mulheres presas demonstraram, cada uma à sua vista, a angústia de estar longe de sua família, a preocupação com aquilo que se passa na rua com seus afetos. Como demonstram Carol e Sandra, ao se preocuparem com o bem-estar de suas filhas que, ainda muito pequenas, tiveram o vínculo materno abruptamente interrompidos. Sandra, em 7 de fevereiro de 2018, observou: "[...] a gente sente uma saudade enorme né, que nem eu, sonho muito com minha menina, esses dias sonhei que uma criança tava pedindo um abraço pensei meu Deus do céu, dai sonho muito com minha menina [...]" (SANDRA, 7 fev. 2018).

Nesse mesmo sentido, Mila se mostrou consciente dos atos que praticou. Possivelmente por sua história de vida, reincidente, cuja família do marido está envolvida com a criminalidade, não viu outra alternativa senão a sorte do crime. Hoje, divide cela com a sogra e outras trinta mulheres, enquanto o marido aguarda transferência na galeria ao lado da sua. Na sua fala, aquilo que grande parte de mulheres e mães encarceradas sentem: "você tá ali presa porque você tava fazendo alguma coisa errada e que você queria dar o melhor para os seus filhos, tava querendo cuidar dos teus filhos" (MILA, 1 mar. 2018).

Para Carol, a realidade que vive é conflitante. Moça jovem ainda, cresceu em meio à miséria e ao abandono "se virando como pôde", conheceu a "malandragem" ainda criança, meio de sobrevivência na periferia. Embora tenha passado por muitas situações peculiares durante a infância e a adolescência, foi presa com mais de vinte anos e hoje sofre com a distância da filha menor, que está sob cuidados do pai que não permite visitas, embora residam na mesma cidade. Seus vínculos familiares são mantidos com a mãe, que se esforça para visitar a filha, embora resida em outro estado: "para mim, é complicado, porque eu não consigo ver a minha filha, a minha mãe mora em Santa Catarina, vem uma vez ou duas por mês" (CAROL, 27 fev 2018).

Essa distância dos entes queridos manifesta-se de maneiras distintas, e podem surgir enquanto presságios do subconsciente, como relatou Sandra a respeito dos constantes sonhos com sua filha e a consequente angústia: os filhos homens estão presos em unidades prisionais distintas da Cadeia Pública de Guarapuava e a filha, que a entrevistada apresenta com dez anos, está sob cuidados de uma tia em Curitiba/PR.

Sandra, que relatou vir de uma vida difícil trabalhando como empregada doméstica em "casas de família", demonstrou-se especialmente preocupada com o aspecto da alimentação, sua e da filha: "[...] me lembro tudo que a gente vai comer o que tem ai se lembra nela tudo né, daí esses já é um dos motivos, agora pra quem não tem filho não tem família assim que é uma, uma pessoa é uma mulher sem filho, daí acho que torna mais fácil pra tá aqui [...]a minha filha bem dizer ela tá sofrendo mais do que eu aqui dentro da cadeia." (SANDRA, 7 fev. 2018).

Essa preocupação com a família, ao mesmo passo em que a memória oscila no tempo, quando se perde acerca da idade da filha menor, mostra, além da saudade e do desejo de liberdade, como o tempo passa de forma diferente dentro da cadeia. Um tempo mais demorado, certamente limitado e sufocado. Tal perspectiva temporal está também na fala de Helena, que, compassivamente, aguarda dia após dia pela liberdade, na fala melancólica que carrega: "mas é muito triste lá dentro [...] você olha lá o sol tá alto, passa parece que uma eternidade, você olha de novo lá o sol, então não passa o tempo lá dentro, você não tem nada pra fazer, anda de um lado pra outro, levanta de onde estava, você dá de cara com a grade, é muito triste, sabe" (HELENA, 26 fev. 2018).

Helena demonstrou que a ocupação é essencial à sobrevivência nesse ambiente e todas afirmaram ter que evitar pensar nessa questão "para não pirar": "aqui na cozinha onde eu tô trabalhando o ambiente é diferente, sabe, porque aqui você conversa, você tem mais 
liberdade, não liberdade de ir pra fora, de sair né, mas tem liberdade pra andar e você tá trabalhando, o tempo passa [...]" (HELENA, 26 fev. 2018).

Embora tenham consciência dos períodos que permanecerão privadas de suas liberdades, todas as entrevistadas demonstraram a esperança de que, talvez numa guinada do destino, seu momento chegue antes, seja antecipado. Percebemos isso na fala de Carol (27 fev 2018) quando afirmou: "assim a gente cresce, amadurece dentro de uma cadeia muitas vezes sai melhor outras vezes sai pior [...]". A esperança do milagre também faz surgir entre essas mulheres uma rede de solidariedade. Muito embora estejam obrigadas a conviver com outras até então estranhas, desperta-Ihes também a empatia: "e das tipo lá de dentro da cela eu não tenho muita coisa pra falar porque eu fiquei só três dias, mas elas me receberam muito bem, elas me ajudaram, eu não tinha no primeiro dia que eu vim sem roupa, sem produto de higiene, nada, então elas me ajudaram assim, não tenho nada pra dizer delas" (HELENA, 26 fev. 2018).

O sentimento de gratidão e cooperação aparece quase que instantaneamente com a prisão. Como demonstrou Helena, que atualmente está alojada na cozinha e cuja fala é corroborada por Mila, que está na cela: "não é assim, tipo, eu vou lá comer, eu vou fazer uma comida só pra mim, não, tipo tem o dia certo, tipo hoje é o meu dia de fazer comida, eu vou cozinhar pra todo mundo do meu barraco, eu vou cozinhar pra quinze meninas entendeu, dai todas quando terminar de fazer comida eu vou avisar oh ta pronta a comida todas vão comer, entendeu?" (MILA, 1 mar. 2018).

Mulheres presas estão, sobretudo, vivenciando uma realidade comum e imposta, em que as individualidades, embora possam ser conflitantes, ao mesmo tempo mostram-se sinônimas. A dor, a angústia, a tristeza, a esperança e o conformismo permeiam suas falas, são histórias de vidas distintas que se cruzam num ambiente e numa realidade amargas. Ironicamente, é momento propício para demonstrar mais uma vez suas forças; essa força da mulher é fator preponderante para o enfrentamento dessa realidade e se mostra presente em cada uma delas.

Quanto aos mecanismos de poder sobrepostos às mulheres presas, ainda que de maneira inconsciente, todas relatam, dentro de sua história e das suas concepções do sistema, verdades que se cruzam, demonstrando, por seus relatos orais, as privações que sofrem. Seja pela segregação institucional, seja pelos espaços a que são destinadas, quando a pena vai muito além da liberdade e atinge também o papel social que lhes cabe.

\section{A necessidade de uma mirada a partir do gênero}

Quando trata da posição feminina no aspecto de comunidade, Simone de Beauvoir (2009 [1949], p. 21) admite que à mulher sempre foi imposto papel relegado. A autora, ao tratar o comportamento humano como uma situação do ser independente do gênero, explica que "as ciências biológicas e sociais não acreditam mais na existência de entidades imutavelmente fixadas, que definiram determinadas características como as da mulher, do judeu ou do negro" (BEAUVOIR, 2009 [1949], p. 14). Sendo assim, a luta feminina deparase com a violência nos mais diversos setores. Quanto ao sistema prisional, não seria diferente.

Joan Scott (1995, p.73) argumenta que a disputa de gênero se mantém firme até a atualidade. Visto que a gramática, de modo geral, classifica fenômenos de classes que categorizam os indivíduos e os dividem em grupos distintos, destaca que as linhas de pesquisa de inclusão da mulher puderam ser diversificadas com o surgimento do feminismo.

De modo geral, as mulheres presas, no Brasil, não estão privadas apenas da liberdade, mas também de seu direito à intimidade, à maternidade, à privacidade, à saúde, dentre outras garantias fundamentais.

Não se trata, no entanto, de uma questão atrelada unicamente à privação de liberdade da pessoa, mas sim à privação da liberdade da mulher, ou seja, a privação de gênero, pois o instituto da prisão no Brasil, tal qual em todas as demais áreas sociais, ainda é dominado pela conceituação de gênero. 
Essa justificativa natural da diferença, que fora socialmente construída na distinção entre o corpo masculino e o corpo feminino (diferença biológica), impõe o homem como "transcendental histórico" e a mulher "construída do ponto de vista dos dominantes às relações de dominação". É justamente neste momento que a violência simbólica ocorre, naturalizando a relação de dominação.

$\mathrm{Na}$ concepção crítica de Butler (1987, p. 151), exigir a mulher enquanto sujeito estável é dizer que não se pode contrapor politicamente seu papel. Recusa-se a autora ao entendimento estático desde seu surgimento, com o papel social pré-definido conforme outrora afirmado. Em razão disso, ela entende que a construção dos papéis sociais se dá através de processos de construção e desconstrução histórica. Para Butler (1987, p. 142143), o gênero não é fenômeno linear, mas inconstante, que não denotaria um ser substantivo, mas um ponto relativo de convergência entre conjuntos específicos de relações cultural e historicamente convergentes. Assim sendo, não existe uma identidade de gênero por trás das expressões de gênero, uma vez que a identidade é constituída pelos passos e descompassos de cada sujeito, quando afirma que "nós nos tornamos nossos gêneros e não nossos sexos".

Nesse mesmo sentido, aliada ao pensamento criminológico, Vera Regina Pereira de Andrade (2005, p. 75) destaca o sistema criminológico como sistema social de controle, seletivo e desigual, tanto de homens como de mulheres, [...] sistema de violência institucional que exerce seu poder e seu impacto também sobre as vítimas.

Samantha Buglione (2000) também destaca esse aspecto oculto do direito penal, afirmando que, apesar de apresentar inclinação no sentido de defesa da sociedade e proteção de bens jurídicos fundamentais, o sistema penal, no seu tratamento às mulheres, é um reflexo da posição social designada a elas, em que o modelo do Estado democrático de direito, cujo principal alicerce é a dogmática jurídica, insere valores na construção da norma pautados na condição de gênero.

Para Espinoza (2004, p. 166), a prisão da mulher é uma faceta social, correspondente ao espaço de reprodução das condições de exclusão e inferiorização que já ocorrem no ambiente extramuros, sendo a prisão um local que "[...] intensifica os defeitos da sociedade de forma perversa, porque, ao controlar todos os aspectos da vida dos indivíduos e fazê-los dependentes de uma autoridade externa".

Para Yumi Miyamoto e Loísio Krohling (2012, p. 239), dentro do contexto de sistema prisional são maiores as desigualdades de gênero.

Considerando que os papéis de gênero se constroem socialmente, observa-se no sistema prisional uma segunda chancela dessa construção desigual, que, além de trazer e de reafirmar a estrutura de poder foucaultiana, também reafirma os arquétipos de desigualdade com a mulher.

\section{Considerações finais}

O sistema prisional brasileiro está imerso em uma profunda crise, onde a supressão de direitos e garantias fundamentais dos presos está consagrada. E naquilo que diz respeito ao encarceramento feminino, a supressão de direitos é proporcionalmente ainda maior, diante da ausência de iniciativas públicas que observem as necessidades próprias das mulheres encarceradas, em razão de sua condição de gênero.

Conforme pode-se observar das informações expostas, as mulheres encarceradas possuem condições específicas de vulnerabilidade e demandam atenção especial do Estado que viola de modo acentuado inúmeros direitos das mulheres encarceradas. Desde a distração em relação aos direitos essenciais como à saúde, até ao direito à vida, ou àqueles implicados numa política de reintegração social, como o trabalho, a educação e a preservação de vínculos e relações familiares; ao se observar a existência de apenas duas unidades destinadas ao recebimento de presas provisórias e de regime fechado, mais uma unidade para presas condenadas ao cumprimento de pena em regime semiaberto. 
Ressalta-se a ausência de informações concretas acerca das unidades prisionais femininas; e ressalta-se que, quando existentes, as informações são contraditórias com dados colhidos a partir do acompanhamento efetivo das unidades, que se mostram esquecidas e invisíveis no sistema penitenciário.

Se há alguma possibilidade de que o sistema prisional promova uma recuperação da pessoa presa, atendendo às expectativas sociais estabelecidas sobre o próprio sistema, ela está essencialmente na recriação dos vínculos com os círculos familiares e de amizade. Para Lemgruber (1999, p. 8), "a importância do contato com a família é múltipla e representa, antes de mais nada, o vínculo com o mundo exterior. Quando este vínculo não pode ser mantido, o sofrimento é imenso" (LEMGRUBER, 1999, p. 8).

Considerar a superlotação das unidades prisionais, com o aumento diário do número de prisões, de condenações e de dureza na penalidade não é ato preventivo ao crescimento da criminalidade.

Foucault acertadamente defendia que a prisão funciona como um instrumento de recrutamento. Mecanismo que torna o preso indesejável à sociedade, profissionalizando o indivíduo para voltar a delinquir posteriormente à prisão por faltar a ele alternativas de agir diferente.

Embora a pessoa que passe pela experiência do sistema prisional carregue consigo essa etiqueta social do delinquente, apta ao seu retorno, de acordo com o analisado acerca do gênero, conclui-se, portanto, que, na estrutura atual edificada do sistema carcerário brasileiro, a mulher está invariavelmente sujeita à dupla estrutura do poder. A primeira delas pela naturalização da dicotomia de gênero socialmente aceita e a segunda pelo poder estatal, que, embora esteja estruturado para punir a pessoa delinquente, legitima dentro de suas estruturas a relação de poder hierarquizada, permitindo-nos concluir verdadeira a premissa de que o sistema prisional é construído por homens e para homens, fechando seus olhos frente à latente existência de mulheres nesse contexto.

Observamos, portanto, que a história do encarceramento feminino é uma história de apagamentos, que se refletem na escassez de dados voltados à sistemática carcerária. Contraditória seria a existência de dados focados especialmente às mulheres, enfatizandose que medidas imediatas devem ser tomadas a fim proporcionar às mulheres encarceradas visibilidade dentro do sistema penitenciário, garantias individuais e meios de enfrentamento das situações de violência de gênero.

\section{Referências}

ALBERTI, V. História oral: a experiência do CPDOC. Rio de Janeiro: FGV, 1990.

AMORIM, C. O Brasil e os direitos humanos: em busca de uma agenda positiva. Política Externa. São Paulo, v. 18, n. 2, p. 67-75, 2009.

ANDRADE, V. R. P. A soberania patriarcal: o sistema de justiça criminal no tratamento da violência sexual contra a mulher. Sequência, Florianópolis, n. 50, p. 71-102, 2005.

ARAUJO, C. E. M. de. Da casa de correção da corte ao Complexo Penitenciário da Frei Caneca: um breve histórico do sistema prisional no Rio de Janeiro, 1834-2006. Revista do Arquivo Geral da Cidade do Rio de Janeiro. Rio de Janeiro, n. 1, p. 147-161, 2007. BECCARIA, C. Dos delitos e das penas. Rio de Janeiro: Nova Fronteira, 2011 [1764]. BEAUVOIR, S. de. O segundo sexo. 2. ed. Rio de Janeiro: Nova Fronteira, 2009. [1949]. BITENCOURT, C. R. Falência da pena de prisão: causas e alternativas. 5. ed. São Paulo: Saraiva, 2017.

BRAGA, A. G.; ALVES, P. Prisão e políticas públicas uma análise do encarceramento feminino no estado do Ceará. Pensar - Revista de Ciências Jurídicas. Fortaleza, v. 20, n. 2, p. 302-326, 2015. 
BRASIL. Conselho Nacional de Justiça. Regras de Bangkok: Regras das Nações Unidas para o Tratamento de Mulheres Presas e Medidas Não Privativas de Liberdade para Mulheres Infratoras/Conselho Nacional de Justiça, Departamento de Monitoramento e Fiscalização do Sistema Carcerário e do Sistema de Execução de Medidas Socioeducativas, Conselho Nacional de Justiça. Brasília: Conselho Nacional de Justiça, 2016.

Lei de Execução Penal. Lei n 7.210/84. De 11 de julho de 1984.

ONU Brasil. Conselho Nacional de Justiça publica versão em português de regras da ONU sobre detenção de mulheres. Brasília, 2016.

ONU BRASIL. Brasil recebe centenas de recomendações para combater violações aos direitos humanos. Brasília, 2017.

BUGLIONE, S. A mulher enquanto metáfora do direito penal. Discursos Sediciosos Crime Direito e Sociedade. Rio de Janeiro, n. 9/10, 2000.

BUTLER, J. Corpos que pesam: sobre os limites discursivos do "sexo. In: LOURO, G. L. (Org.) O corpo educado: pedagogias da sexualidade. Belo Horizonte: Autêntica, 2010.

Problemas de gênero: feminismo e subversão da identidade. Rio de Janeiro: Civilização Brasileira, 2010.

Variações sobre sexo e gênero: Beauvoir, Wittig e Foucault. In: BENHABIB, S.; CORNELL, D. (Orgs.) Feminismo como crítica da modernidade. Rio de Janeiro: Rosa dos Tempos, 1987. p. 139-154.

CARDOSO, M. C. V. As assistências previstas na Lei de Execução Penal: uma tentativa de inclusão social do apenado. Ser Social. Brasília, v. 11, n. 24, p. 106-128, 2009.

CAROL. Entrevista. Entrevistadora: Fernanda Bugai. Guarapuava, 27 fev. 2018. 1 arquivo mp3 (60 minutos).

CERNEKA, H. A. Homens que menstruam: considerações acerca do sistema prisional às especificidades da mulher. Veredas do Direito. Belo Horizonte, v. 6, n. 11, p. 61-78, 2009.

CHIES, L. A. B.; VARELA, A. B. A ambiguidade do trabalho prisional num contexto de encarceramento feminino: o círculo vicioso da exclusão. In: CONGRESSO BRASILEIRO DE SOCIOLOGIA, 13., 2007, Recife. Anais [...] Recife: Sociedade Brasileira de Sociologia, 2007.

CITELLI, M. T. Fazendo diferenças: teorias sobre gênero, corpo e comportamento. Estudos Feministas. Florianópolis, v. 9, n. 1, p. 131-145, 2001.

COLARES, L. B. C.; CHIES, L. A. B. Mulheres nas so(m)bras: invisibilidade, reciclagem e dominação viril em presídios masculinamente mistos. Estudos Feministas, Florianópolis, v. 18, n. 2, p. 407, jan. 2010.

DINIZ, D. Cadeia: relatos sobre mulheres. Rio de Janeiro: Civilização Brasileira, 2015.

DI SANTIS, B. M.; ENGBRUCH, W. A evolução histórica do sistema prisional e a

Penitenciária do Estado de São Paulo. Liberdades. São Paulo, n. 11, p. 143-160, 2017.

ESPINOZA, O. A mulher encarcerada em face do poder punitivo. São Paulo: IBeCRIM, 2004.

FOUCAULT, M. História da sexualidade. 13.ed. Rio de Janeiro: Graal, 1999. (1: A vontade de saber)

Vigiar e punir: nascimento da prisão. Petrópolis: Vozes, 2014.

FRINHANI, F. de M. D.; SOUZA, L. de. Mulheres encarceradas e espaço prisional: uma análise de representações sociais. Psicologia: Teoria e Prática. São Paulo, v. 7, n. 1, p. 61-79, 2005. 
GARUTTI, S.; OLIVEIRA, R. de C. da S. A prisão e o sistema penitenciário: uma visão histórica. SEMINÁRIO DE PESQUISA DO PPE, 2012., Maringá. Anais [...] Maringá: Universidade Estadual de Maringá, 2007. Disponível em:

<http://www.ppe.uem.br/publicacoes/seminario_ppe_2012/trabalhos/co_02/036.pdf> Acesso em: 1 dez. 2012.

GONÇALVES, P. C. A era do humanitarismo penitenciário: as obras de John Howard, Cesare Beccaria e Jeremy Benthan. Revista da Faculdade de Direito da UFG. Goiânia, v. 33, n. 1, p. 9-17, 2009.

GRÄSSEL, E.; SCHIRMER, B. The use of volunteers to support family careers of dementia patients: results of a prospective longitudinal study investigating expectations towards and experience with training and professional support. Zeitschrift Fur Gerontologie Und Geriatrie. Berlin, v. 39, n. 3, p. 217-226, 2006.

GRECO, R. Sistema prisional: colapso atual e soluções alternativas. Niterói: Impetus, 2016.

HELENA. Entrevista. Entrevistadora: Fernanda Bugai. Guarapuava, 26 fev. 2018. 1 arquivo mp3 (60 minutos).

ISLAM, M. J.; SUBATRA, B. Theories of female criminality: a criminological analysis.

International Journal of Criminology and Sociological Theory. Toronto, v. 7, n. 1, p. 1-8, 2014.

LEMGRUBER, J. Cemitério dos vivos: análise sociológica de uma prisão de mulheres. Rio de Janeiro: Forense, 1999.

LORA Alarcón, P. de J. Constitucionalismo e Direitos Humanos: algumas reflexões sobre o caráter de nossa época. Revista da Faculdade de Direito de São Bernardo do Campo. São Bernardo do Campo, n. 13, p. 244-245, 2007.

MAIA, C. N. História das prisões no Brasil. Rio de Janeiro: Rocco, 2009.

MENDES, S. da R. Criminologia feminista. São Paulo: Saraiva, 2014.

MILA. Entrevista. Entrevistadora: Fernanda Bugai. Guarapuava, 1 mar. 2018. 1 arquivo mp3 (60 minutos).

MINISTÉRIO DA JUSTIÇA. Departamento Penitenciário Nacional. Levantamento de informações penitenciarias Infopen. Dezembro 2014. Brasília: Ministério da Justiça, 2014. Disponível em: <https://www.conjur.com.br/dl/infopen-dez14.pdf> Acesso em: 30 dez. 2014.

MIYAMOTO, Y.; KROHLING, A. Sistema prisional brasileiro sob a perspectiva de gênero: invisibilidade e desigualdade social da mulher encarcerada. Direito, Estado e Sociedade. Rio de Janeiro, n. 40, p. 223-241, 2012.

MORES, L.; BRETAS, M. Entrevista com Marcos Luiz Bretas da Fonseca. In: KLANOVICZ, L. R. F. (Org.) Trajetórias acadêmicas de historiadoras e historiadores. Curitiba: CRV, 2017. p. 105-112.

OLIVEIRA, M. G. F.; SANTOS, A. F. P. R. Desigualdade de gênero no sistema prisional: considerações acerca das barreiras à realização de visitas e visitas íntimas às mulheres encarceradas. Caderno Espaço Feminino. Uberlândia, v. 25, n. 1, p. 236-246, 2012.

PESAVENTO, S. J. Visões do cárcere. Porto Alegre: Zouk, 2009.

PIMENTEL, E. As mulheres e a vivência pós-cárcere. Maceió: Editora da UFAL, 2015.

PONTES, F.; MARTINS, H. (2018). População carcerária feminina cresce $700 \%$ em dezesseis anos no Brasil. Agência Brasil. Agência Brasil. Disponível em:

$<$ http://agenciabrasil.ebc.com.br/direitos-humanos/noticia/2017-08/populacao-carcerariafeminina-cresce-700-em-dezesseis-anos-no>. Acesso em: 12 maio 2018. 
QUEIROZ, M. L. de. A abordagem feminista das relações internacionais e violações de Direitos Humanos no Brasil. Uma discussão sobre o sistema prisional. Transgressões. Natal, v. 3, n. 2, p. 5-31, 2015.

RIBEIRO JUNIOR. A história e a evolução do Direito Penal brasileiro. Brasília: Conteúdo Jurídico, 2009.

SALLA, F. As prisões em São Paulo: 1822-1940. São Paulo: Annablume; Fapesp, 2006.

SANDRA. Entrevista. Entrevistadora: Fernanda Bugai. Guarapuava, 7 fev. 2018. 1 arquivo mp3 (60 minutos).

SCHERER, Z. A. P.; SCHERER, E. A.; NASCIMENTO, A. D.; RAGOZO, F. D. Perfil sociodemográfico e história penal da população encarcerada de uma penitenciária feminina do interior do estado de São Paulo. SMAD: Revista Eletrônica Saúde Mental Álcool e Drogas. São Paulo, v. 7 n. 2, p. 55-62, 2011.

SCOTT, J. Gênero: uma categoria útil para a análise histórica. Educação e Realidade. Porto Alegre, v. 20, n. 2, p. 71-99, 1995.

VARELLA, D. Carcereiros. São Paulo: Companhia das Letras, 2012.

Estação Carandiru. São Paulo: Companhia das Letras, 1999.

Prisioneiras. São Paulo: Companhia das Letras, 2017.

VERDÉLIO, A. Com 726 mil presos, Brasil tem terceira maior população carcerária do mundo. Agência Brasil. Disponível em: <http://agenciabrasil.ebc.com.br/geral/noticia/201712/populacao-carceraria-do-brasil-sobe-de-622202-para-726712-pessoas> Acesso em: 11 mar. 2017.

WALKLATE, S. Can there be a feminist victimology? In: DAVIES, P.; FRANCIS, P.; JUPP, V. (Orgs.) Victimisation: theory, research and policy. Basingstoke: Palgrave Macmillan, 2003. p. 28-45.

ZAINAL, Z. Case study as a research method. Jurnal Kemanusiaan. Pulau Pinang, v. 9, p. 1-6, 2007. 